\title{
Pre-transplant heart disease etiology has a major effect on post-transplant survival of patients bridged with heartmate II assist device
}

\author{
M Urban ${ }^{*}$, J Pirk, O Szarszoi, I Netuka \\ From 23rd World Congress of the World Society of Cardio-Thoracic Surgeons \\ Split, Croatia. 12-15 September 2013
}

\section{Background}

Left ventricular assist devices (LVAD) have become an established mode of treatment in bridging patients with advanced heart failure to cardiac transplantation. In certain groups of patients LVADs have proven their efficacy as a destination therapy. Increasing mismatch between the expanding pool of heart failure patients and decline in availability of donor organs raises an important question of prioritizing patients on the waiting list.

\section{Methods}

This is a retrospective analysis of post-transplant results of patients bridged with HeartMate II. Patients were divided based on pre-transplant etiology into ischemic, non-ischemic and congenital group. One-year post-transplant survival was calculated using the Kaplan-Meier method and Log-rank test was used for comparison.

\section{Results}

Between 2007 and 201360 patients were transplanted from HeartMate II at our institution. There were no differences in patients' pre-transplant demographic and clinical variables. Donor characteristics as well as ischemic times were also comparable. Overall one-year post-transplant survival was $90 \pm 2 \%$. Patient with nonischemic etiology had $97 \pm 3 \%$ survival compared to 86 $\pm 7 \%$ in patients with ischemic and $67 \pm 19 \%$ in patients with congenital heart disease $(\mathrm{p}=0.043)$.

\section{Conclusion}

Our data indicate that patients with congenital heart disease bridged to transplantation with HeartMate II

\footnotetext{
* Correspondence: maub@kem.cz

Department of Cardiac Surgery, Institute for Clinical and Experimental Medicine, Prague, Czech Republic
}

(c) 2013 Urban et al; licensee BioMed Central Ltd. This is an Open Access article distributed under the terms of the Creative Commons Attribution License (http://creativecommons.org/licenses/by/2.0), which permits unrestricted use, distribution, and reproduction in any medium, provided the original work is properly cited. have significantly reduced one-year post-transplant survival compared to patients with other cardiomyopathies. In the era of the current donor shortage, there is an increased pressure at judicious utilization of resources and surgical outcomes are increasingly scrutinized. Every effort should be made at identifying risk factors for diminished post-transplant survival. We believe that advancements in LVADs technical design associated with improved survival and quality of life make new generation devices a viable alternative as a definitive treatment option for a very high risk transplant patients.

Published: 11 September 2013

doi:10.1186/1749-8090-8-S1-0155

Cite this article as: Urban et al:: Pre-transplant heart disease etiology

has a major effect on post-transplant survival of patients bridged with

heartmate II assist device. Journal of Cardiothoracic Surgery 2013 8(Supp 1):0155.

Submit your next manuscript to BioMed Central and take full advantage of:

- Convenient online submission

- Thorough peer review

- No space constraints or color figure charges

- Immediate publication on acceptance

- Inclusion in PubMed, CAS, Scopus and Google Scholar

- Research which is freely available for redistribution 